\title{
Passive Immunity in Ontario Dairy Calves and Investigation of Its Association with Calf Management Practices
}

\author{
L. A. Trotz-Williams, K. E. Leslie, ${ }^{1}$ and A. S. Peregrine \\ Ontario Veterinary College, University of Guelph, Guelph, Ontario N1G 2W1, Canada
}

\begin{abstract}
Adequate passive transfer of maternal immunoglobulin is important for optimal health and performance in newborn dairy calves. From June to October 2003 and January to April 2004, blood samples were collected from 961 dairy calves 0 to $8 \mathrm{~d}$ of age on 11 farms in southwestern Ontario. This was followed by a second study conducted from May to October 2004, in which similar samples were taken from 422 calves up to $8 \mathrm{~d}$ of age on 119 dairy farms throughout southern Ontario. For each sample collected, serum refractometry was used to evaluate serum total protein (TP) as a measure of passive transfer of maternal immunity. During each study, producers were asked to provide information on calf management practices, including details of colostrum feeding. Data were analyzed to assess the levels of maternal immunity present in the calves, and to investigate whether these were associated with any calf management or colostrum feeding practices used on the farms. Serum TP readings ranged from 3.5 to 9.8 $\mathrm{g} / \mathrm{dL}$. Controlling for any effects of variation between farms, we found no statistically significant difference in serum TP levels, or risk of failure of passive transfer (FPT), between heifer and bull calves. The odds of FPT in calves on farms where more than $75 \%$ of cows were usually allowed to remain with their calves for more than $3 \mathrm{~h}$ after calving were significantly higher than the odds of FPT in calves on farms where dams and calves were separated within $3 \mathrm{~h}$ of the birth. Furthermore, an increased volume of colostrum given to calves within $6 \mathrm{~h}$ of birth was significantly associated with a reduced risk of FPT in calves. Information from this work provides valuable insight into the efficiency of passive transfer in newborn dairy calves in southern Ontario.
\end{abstract}

Key words: calf, failure of passive transfer, maternal immunity, risk factor

Received November 27, 2007.

Accepted May 23, 2008.

${ }^{1}$ Corresponding author: keleslie@uoguelph.ca

\section{INTRODUCTION}

There is a recognized association between calf morbidity and mortality, and low levels of maternal Ig transfer to neonatal calves (Paré et al., 1993; Donovan et al., 1998; Virtala et al., 1999). Calves with lower levels of passive immunity have been found to show reduced daily gains in the first few months of life (Robison et al., 1988). Poor performance, morbidity, and mortality among dairy calves result in increased production costs and reduced profitability for the dairy industry as well as for veal operations. Therefore, it is important to ensure that dairy calves receive an adequate quantity of good-quality (high $\operatorname{IgG}_{1}$ ) colostrum within the first hours of life to facilitate optimal passive transfer of maternal Ig from dam to calf (Morin et al., 1997; Jaster 2005).

Passive transfer of immunity in calves may be assessed by several methods, including direct measurement of serum IgG by ELISA or radial immunodiffusion (Filteau et al., 2003) and estimation of serum IgG concentration by measuring serum total protein (TP) by refractometry (Wallace et al., 2006). The latter method has been reported to be a reliable screening test for the assessment of passive transfer in calves, with a sensitivity and specificity of greater than $80 \%$, when test end points of 5.0 or $5.2 \mathrm{~g} / \mathrm{dL}$ are used for diagnosis of failure of passive transfer (FPT; Calloway et al., 2002).

To date, several reports have been published on factors associated with the acquisition of passive immunity in newborn calves in the United States (Besser et al., 1991; Perino et al., 1995; Quigley et al., 2001) and in Quebec, Canada (Filteau et al., 2003). However, there is a lack of published information of this kind in relation to dairy calves in Ontario, Canada. Such information is important to determine whether additional measures need to be taken by the industry to ensure adequate transfer of passive immunity to calves entering the dairy and veal industries, and to investigate whether calf management practices prevalent in the province may have an effect on the risk of FPT. Furthermore, there is concern that calves entering the veal industry from dairy farms may not be receiving adequate quan- 
tities of colostrum and, as a result, may suffer from greater rates of FPT than replacement dairy heifers. Therefore, in the work reported here, data collected on southern Ontario dairy farms during 2 large dairy calf health studies conducted in 2003 and 2004 were analyzed to assess passive immunity in calves up to $8 \mathrm{~d}$ of age on southern Ontario dairy farms. In addition, these data were investigated to determine whether the level of acquisition of passive immunity in these calves was associated with colostrum feeding methods and other calf management practices.

\section{MATERIALS AND METHODS}

\section{Description of Herds and Data Collection}

Data analyzed in this study consisted of farm management information and calf serum TP measurements collected during 2 observational studies conducted in 2003 and 2004. Details of data collection and herds have been published elsewhere (Trotz-Williams et al., 2007a,b). Briefly, in the first project (Trotz-Williams et al., 2007a), referred to hereafter as the calf-level study, the primary purpose of the work was to investigate whether any associations existed between management practices and the risk of Cryptosporidium parvum shedding in dairy calves. In this project, weekly visits were made to 11 dairy farms in southwestern Ontario from June to October 2003 and January to April 2004. The number of milking cows per farm ranged from 60 to 950, and all cows were Canadian Holsteins. At each visit, a jugular blood sample was collected in a plain (no anticoagulant: red top) 10-mL Vacutainer tube (Becton Dickinson and Co., Franklin Lakes, NJ) from each calf born since the previous visit (up to $8 \mathrm{~d}$ of age). This sample was collected from calves that were clinically normal as well as from those that were showing signs of diarrhea at the time of the visit, and was used to assess passive transfer of maternal immunity by serum refractometry. Producers were asked to complete a questionnaire on calf management methods for each calf, including methods used to collect, store, and feed colostrum.

The second study (referred to hereafter as the herdlevel study) was carried out from May to October 2004 on 119 dairy farms throughout southern Ontario (TrotzWilliams et al., 2007b). That study was conducted with the objective of investigating associations between farm management practices and the within-herd prevalence of C. parvum. Herds of various sizes, and representing several management styles, were included in the study. The number of milking cows per farm ranged from 17 to 950 , with a mean of 95 cows and a median of 70. On most farms, all cows were Canadian Holsteins.
In addition to collection of fecal samples for testing for Cryptosporidium, jugular blood samples were drawn in plain 10-mL Vacutainer tubes (Becton Dickinson and Company) from a maximum of 5 calves on each farm, up to and including $7 \mathrm{~d}$ of age. A questionnaire was administered on each farm to gather information on farm-level management practices. As in the first study, this questionnaire included questions on colostrum storage and feeding methods used on the farms. However, information collected in this work referred only to herd-level practices to which individual calves had been exposed. Questionnaires from both studies are available from the authors in English.

In each study, blood samples were placed in a cooler immediately after collection and transferred to a refrigerator for storage for up to $24 \mathrm{~h}$. Sera were separated from blood samples within $24 \mathrm{~h}$. Serum refractometry was performed by using a handheld refractometer (SPR-Ne, Atago Company, Kirkland, WA), in accordance with the manufacturers' instructions, to determine serum TP content as a measure of passive transfer of maternal immunity. A test end point (cutoff value) of $5.2 \mathrm{~g} / \mathrm{dL}$ was used; that is, FPT was defined as serum TP concentrations of $<5.2 \mathrm{~g} / \mathrm{dL}$ (Calloway et al., 2002).

\section{Statistical Analysis}

Data were entered into EpiData and Microsoft Access databases and exported into Stata 9.0 (StataCorp LP, College Station, TX) for statistical analysis.

Calf-Level Study. For data from this study, descriptive analyses were carried out to determine the distribution of serum TP levels among the calves, as well as the number of calves exposed to each management practice to be investigated for associations with TP levels and the risk of FPT. For the purposes of this work, FPT was defined as serum TP concentrations below $5.2 \mathrm{~g} /$ dL (Calloway et al., 2002). Mixed effects linear regression was then used to investigate the data collected in this study for any association between serum TP (as a continuous outcome or dependent variable) and sex of the calves (as the independent variable). Mixed effects logistic regression was used to explore the data for any significant association between FPT (as a dichotomous outcome variable) and sex of the calves (as the independent variable). Each model included farm as a random effect to control for any effect of clustering of data within herds. Model diagnostics were performed by generating and examining residuals and expected values (probabilities) of the outcome (Dohoo et al., 2003). Because colostrum-feeding practices were largely at the herd level, and only a small number of farms were represented in the data $(\mathrm{n}=11)$, no analyses were 
undertaken for associations between calf management variables and serum TP levels or FPT.

Herd-Level Study. For these data, descriptive analyses were carried out to determine the distribution of serum TP levels among the calves, as well as the number of farms using each management practice to be investigated for associations with TP levels and the risk of FPT. As for the calf-level data, FPT was defined as serum TP concentrations below $5.2 \mathrm{~g} / \mathrm{dL}$ (Calloway et al., 2002). Mixed effects linear regression was then used to investigate the data for any association between serum TP (as a continuous outcome variable) and sex of calves (as the independent variable). In addition, mixed effects logistic regression was used to explore the data for any association between FPT (as a dichotomous outcome variable) and sex of the calves (as the independent variable). Each mixed model included farm as a random effect to control for the effect of clustering within herds. The same regression methods were used to model management variables (as independent variables) on serum TP (as a continuous outcome variable using linear regression) or FPT (as a dichotomous outcome variable using logistic regression) to look for statistically significant associations. Here again, each model included farm as a random effect to control for the effect of clustering within herds. Associations were examined first by using univariable models, and subsequently by constructing multivariable models that included independent variables that were statistically significant in univariable models. Final multivariable models were produced by using the manual backward elimination procedure described by Dohoo et al. (2003), with a significance level of $P>0.05$ as the criterion for removal of a variable from the model. Model diagnostics were performed by generating and examining residuals and expected values (probabilities) of the outcome (Dohoo et al., 2003).

\section{RESULTS}

From the 2003-2004 calf-level study, individual calf data were available for 961 dairy calves $<1$ to $8 \mathrm{~d}$ of age from 11 southwestern Ontario farms. From the herdlevel study, herd-level management information and calf-level serum TP readings were available for 423 calves $<1$ to $7 \mathrm{~d}$ of age on 119 dairy farms throughout southern Ontario. The results from these 2 studies are presented separately below.

\section{Data from the Calf-Level Study}

Description of Calves. Of the 961 calves in this study, 606 (63.1\%) were born in the warmer months (June to October 2003) and 355 (36.9\%) were born in the following winter (January to April 2004). Information on sex was recorded for 932 of the 961 calves: 355 (38.1\%) were male (bull) calves, 575 (61.7\%) were females (heifers), and 2 calves (0.2\%) were freemartins. Twenty-eight (2.9\%) of the 961 calves were less than 1 $\mathrm{d}$ of age at sampling.

Maternal Immunity and FPT. A highly significant difference $(P<0.001)$ was found between the mean serum TP levels of calves less than $1 \mathrm{~d}$ of age $(5.4 \mathrm{~g} /$ $\mathrm{dL})$ and those of calves $1 \mathrm{~d}$ of age and older $(6.3 \mathrm{~g} / \mathrm{dL})$. Therefore, calves less than $1 \mathrm{~d}$ of age were omitted from all analyses that included serum TP or FPT as an outcome variable. Serum TP measurements for the calves $1 \mathrm{~d}$ of age or older $(\mathrm{n}=933)$ ranged from 3.5 to $8.6 \mathrm{~g} / \mathrm{dL}$ (average $6.3 \mathrm{~g} / \mathrm{dL}$; median $6.3 \mathrm{~g} / \mathrm{dL}$ ) and are summarized in Figure 1. Using a cutoff value (test end point) for FPT of $5.2 \mathrm{~g} / \mathrm{dL}, 78$ (8.4\%) of the 933 calves showed serum TP levels indicative of FPT.

Associations Between Measures of Maternal Immunity and Sex of Calves. Controlling for differences in proportions of male and female calves between farms by using random effects linear regression, we found no statistically significant difference between the serum TP levels of bull and heifer calves $1 \mathrm{~d}$ of age or older $(P=0.991)$. Serum TP concentrations indicated FPT in $60(10.7 \%)$ of 558 heifer calves as opposed to $12(3.5 \%)$ of 347 bull calves; however, when controlling for farm effects by using random effects logistic regression, this difference was also not statistically significant $(P=$ $0.456)$.

Colostrum Feeding Practices. Calf management (including colostrum feeding) methods to which calves were exposed are summarized in Table 1 . Where information on management methods was missing, calves were excluded from counts; therefore, total counts for some variables are less than 961 calves.

As shown in Table 1, although approximately equal proportions (between 20 and 30\%) of the calves in the study were born in each of the four 6 -h periods of the day or night, fewer than $50 \%$ of the calves were allowed to remain with their mothers for more than $1 \mathrm{~h}$ after birth. The calf's mother was reported as the most common source of colostrum given to the calves, with $59.4 \%$ of calves receiving colostrum from their mothers. Pooled colostrum was given to $45.5 \%$ of the calves in the study. Most (75.4\%) of the calves received fresh colostrum, whereas $55.0 \%$ were given colostrum that had been frozen. Most (89.0\%) of the calves were bottlefed colostrum; however, $30.9 \%$ were tube-fed. In fact, 202 calves received colostrum both by bottle and by tube (not shown in Table 1). The amount of colostrum given in each interval of time within the first $24 \mathrm{~h}$ of birth varied from 0 to $4 \mathrm{~L}$ for the first $6 \mathrm{~h}, 0$ to $6 \mathrm{~L}$ for the next $6 \mathrm{~h}$, and 0 to $9 \mathrm{~L}$ for the last $12 \mathrm{~h}(12$ to $24 \mathrm{~h}$ 


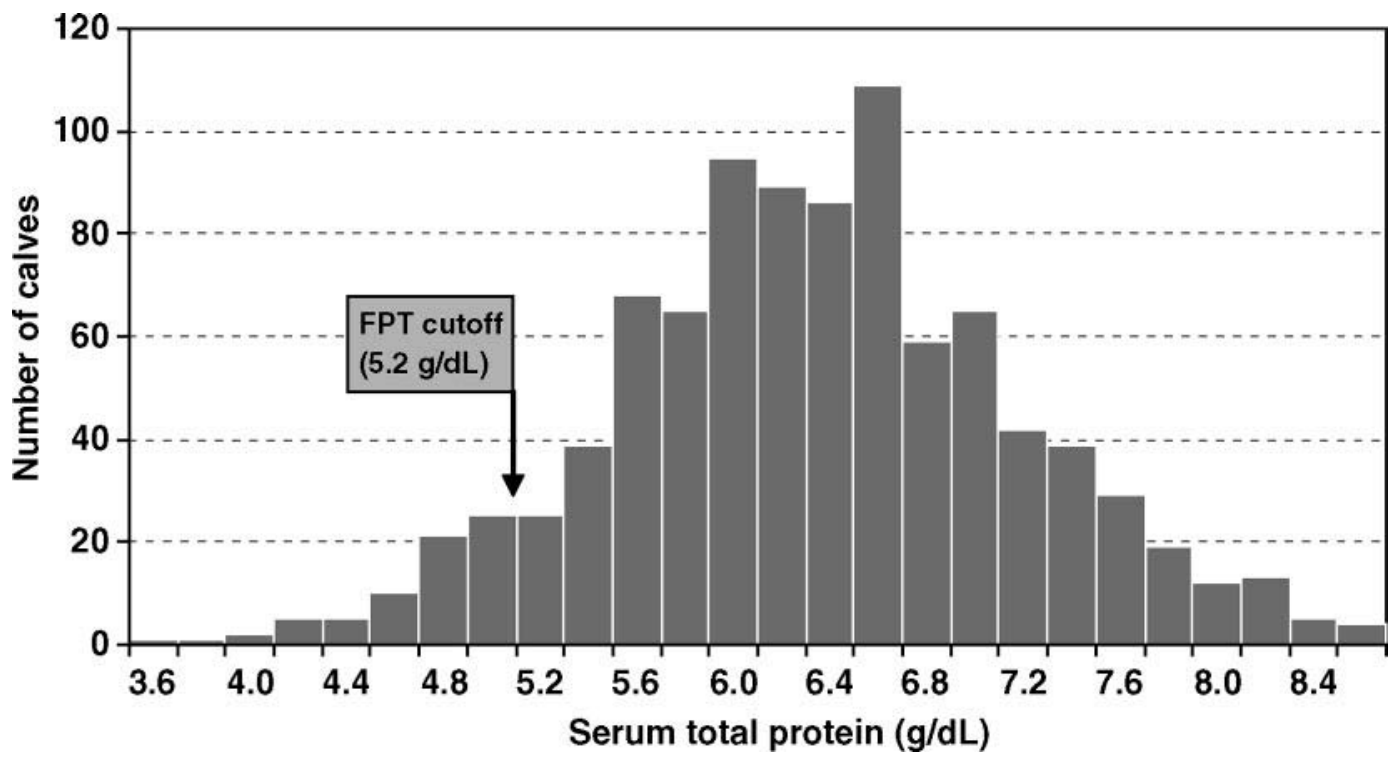

Figure 1. Serum total protein (TP) concentrations in 933 calves 1 to $8 \mathrm{~d}$ of age on 11 southwestern Ontario dairy farms (calf-level study). Results for 78 calves (8.4\%) indicated failure of passive transfer (FPT; serum TP levels $<5.2 \mathrm{~g} / \mathrm{dL}$ ). Calves with FPT were present on all 11 farms.

after birth). In each period, the most commonly stated quantity of colostrum given was $2 \mathrm{~L}$ (not shown in Table 1). Information on the number of feedings represented by these volumes was not collected in the study and is therefore not presented in the table.

\section{Data from the Herd-Level Study}

Description of Calves. Serum TP refractometry readings were available for 423 calves on 112 of the 119 farms in this study. Serum TP concentrations were not measured in calves from the remaining 7 farms; therefore, these were excluded from the analysis. Because recording of the sex of the calves was not relevant to the objectives of the original study, this was done only for some calves. As a result, data on sex were available for only 244 calves from 65 farms. Of these 244 animals, 119 (48.8\%) were males (bull calves) and 125 $(51.2 \%)$ were females (heifers). The ages of 421 calves were known: these ranged from a few hours $(<1 \mathrm{~d})$ to 7 $\mathrm{d}$ of age. Sixteen calves (3.8\%) were less than $1 \mathrm{~d}$ of age at the time of testing.

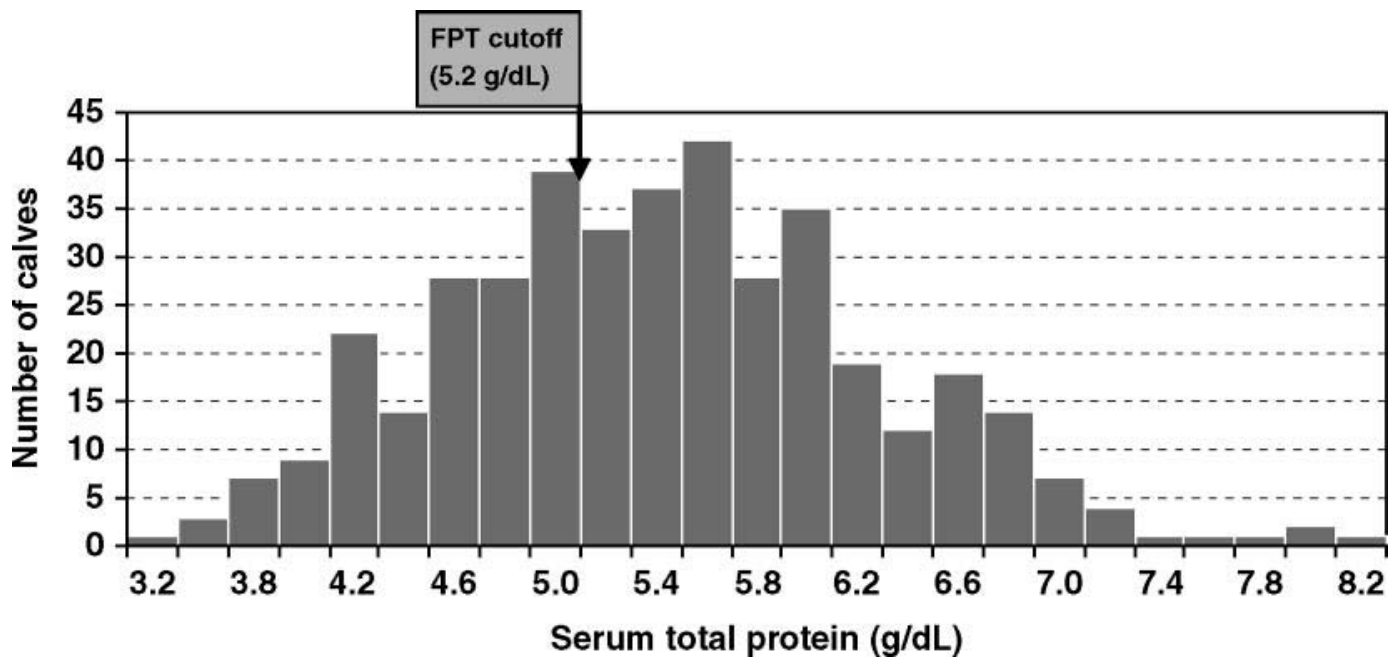

Figure 2. Serum total protein (TP) concentrations in 407 calves 1 to $7 \mathrm{~d}$ of age on 112 southwestern Ontario dairy farms (herd-level study). Results for 151 calves (37.1\%) indicated failure of passive transfer (FPT; serum TP levels $<5.2 \mathrm{~g} / \mathrm{dL}$ ). 
Maternal Immunity and FPT. Serum TP measurements for all calves in this data set ranged from 3.2 to $9.8 \mathrm{~g} / \mathrm{dL}$, with an average of $5.4 \mathrm{~g} / \mathrm{dL}$ and a median of $5.4 \mathrm{~g} / \mathrm{dL}$. Serum TP measurements for calves $1 \mathrm{~d}$ of age and older also ranged from 3.2 to $9.8 \mathrm{~g} / \mathrm{dL}$, with an average of $5.4 \mathrm{~g} / \mathrm{dL}$ and a median of $5.4 \mathrm{~g} / \mathrm{dL}$. For calves in this data set, no significant difference $(P=0.944)$ was found between the mean serum TP levels of calves $<1 \mathrm{~d}$ of age $(5.4 \mathrm{~g} / \mathrm{dL})$ and those of calves $1 \mathrm{~d}$ of age and older $(5.4 \mathrm{~g} / \mathrm{dL})$. Nevertheless, for consistency of approach, calves under $1 \mathrm{~d}$ of age were omitted from all regression analyses that included serum TP or FPT as an outcome (dependent) variable. Serum TP levels for calves 1 to 7 d of age $(n=407)$ are summarized in Figure 2. Withinherd median values ranged from 4.2 to $7.0 \mathrm{~g} / \mathrm{dL}$, with an average of $5.4 \mathrm{~g} / \mathrm{dL}$. Results for 151 calves (37.1\%) indicated FPT (serum TP levels $<5.2 \mathrm{~g} / \mathrm{dL}$ ).

Associations Between Measures of Maternal Immunity and Sex of Calves. As with the data from the calf-level study, mixed effects regression, controlling for the effect of variation between farms, showed that there was no significant difference in serum TP levels $(P=0.276)$ or FPT $(P=0.563)$ between male and female calves for the 232 animals $1 \mathrm{~d}$ of age or older of known sex. Of these 232 animals, $48(41.4 \%)$ of the 116 bull calves and $44(37.9 \%)$ of the 116 heifer calves showed readings indicative of FPT (i.e., serum TP levels $<5.2$ $\mathrm{g} / \mathrm{dL}$ ).

Colostrum Feeding Practices. Table 2 summarizes the calf management and colostrum feeding practices

Table 1. Summary of responses to individual calf questionnaires administered to 11 southwestern Ontario dairy farms on calf management practices (calf-level study)

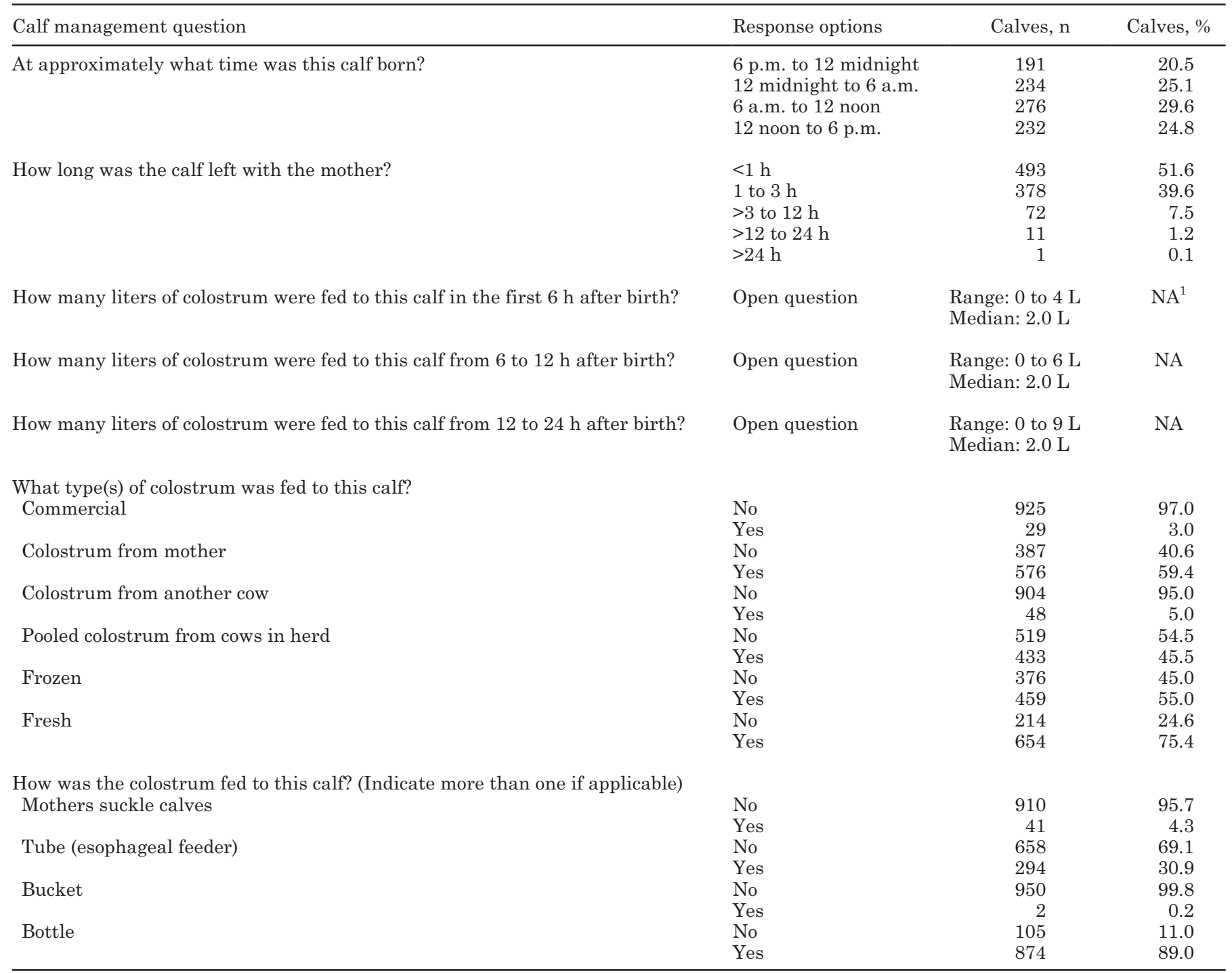

${ }^{1} \mathrm{NA}=$ not applicable. 
Table 2. Summary of responses to herd-level questionnaire administered to 112 southern Ontario dairy farms on herd-level calf management practices (herd-level study)

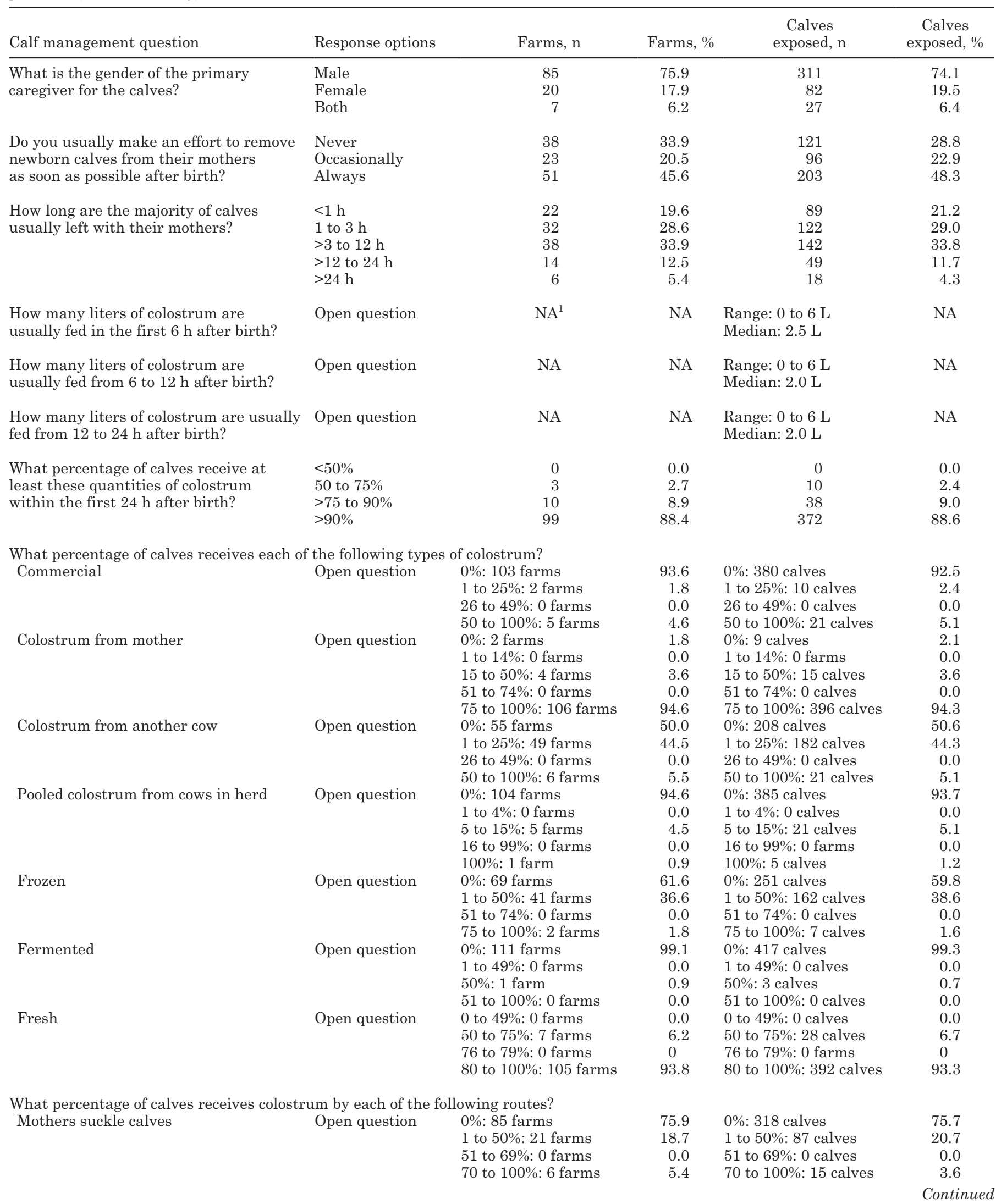


Table 2 (Continued). Summary of responses to herd-level questionnaire administered to 112 southern Ontario dairy farms on herd-level calf management practices (herd-level study)

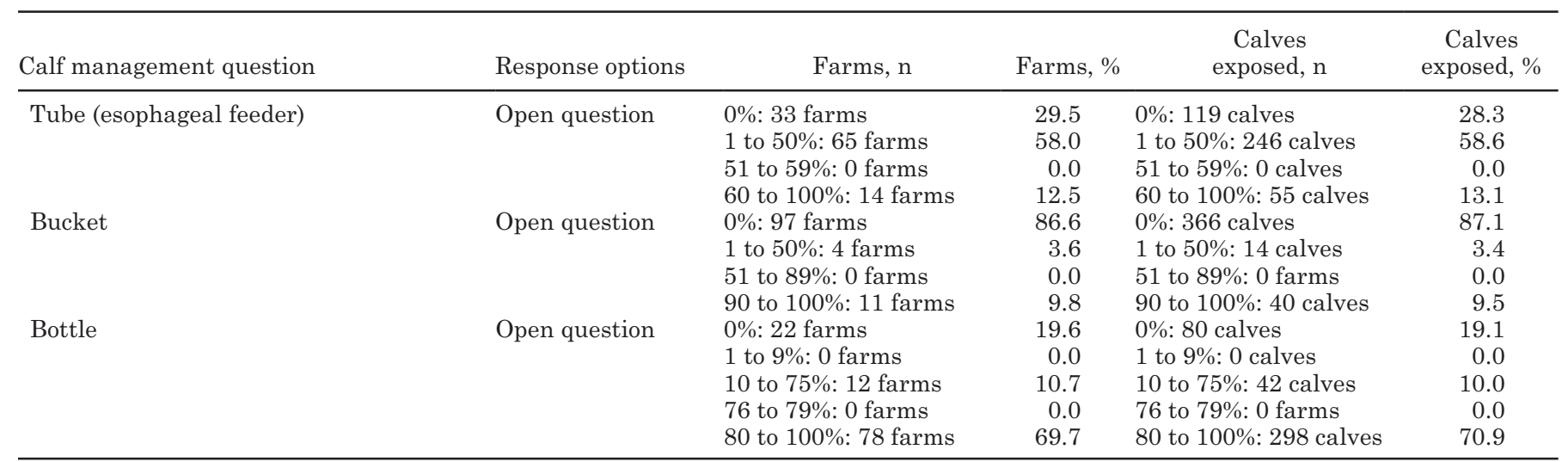

${ }^{1} \mathrm{NA}=$ not applicable.

used on the dairy farms participating in the herd-level study. As in the calf-level study, information was not collected on the number of feedings represented by the quantities of colostrum reported by producers. Where information on management methods was missing, calves or farms were excluded from counts. Therefore, total counts for some variables was less than 423 calves or 112 farms.

Associations Between Calf Management Methods and Serum TP. Univariable random effects linear regression of calf age and management variables (as independent variables) on serum TP (as the outcome variable), using data from the herd-level study for calves 1 to $7 \mathrm{~d}$ of age, showed that serum TP levels did not vary significantly with age of the calves $(P=$ $0.906)$. Calves on farms where the primary calf caregiver was female had significantly greater levels of serum TP than those on farms where the primary calf caregiver was male $(P=0.008$; Table 3$)$. No other calf management variables were significantly associated with serum TP concentrations.

Associations Between Calf Management Methods and Risk of FPT. Results of mixed effects logistic regression revealed that neither age of calves $(P=$ $0.504)$ nor gender of caregiver $(P=0.563)$ was statistically associated with the risk of FPT. However, the odds of FPT in calves on farms where the majority of calves were reported as being allowed to remain with their dams for more than $3 \mathrm{~h}$ after birth were more than twice the odds of FPT in calves on farms where calves were usually separated from their dams within $3 \mathrm{~h}$ of birth (Table 4). The percentage of calves on a farm that were allowed to suckle colostrum directly from their dams, as reported by producers, was also significantly and positively associated with an increased risk of FPT. In other words, calves on farms where a greater percentage of calves were reportedly allowed to suckle from their dams had increased odds of FPT compared with calves on farms where a lower percentage of calves were allowed to suckle. On the other hand, the quantity of colostrum that producers reported giving to calves in the first $6 \mathrm{~h}$ after birth was significantly, and negatively, associated with the risk of FPT: the greater the quantities of colostrum that producers reported giving in the first $6 \mathrm{~h}$ after birth, the lower the odds of FPT in their calves. No other management variables were significantly associated with the risk of FPT ( $P$ $>0.05)$.

A multivariable model, constructed by using the above 3 variables that were significantly associated with the risk of FPT in univariable modeling, gave the results summarized in Table 5. No interactions or confounding was evident during the construction of this model, and examination of residuals and predicted probabilities indicated good model fit.

\section{DISCUSSION}

The data collected and analyzed in this project were obtained from studies that did not have the investigation of FPT as a primary objective. However, those studies involved the collection of samples and data from a large number of calves on dairy farms representing a wide spectrum of management practices and a variety of herd sizes. These farms included those considered normal with respect to calf health issues, as well as some with varying levels of calf diarrhea. Therefore, much of the information gained from investigation of these data is likely to be representative of the true status of dairy calves on farms throughout southern Ontario. This is especially true of the range of serum TP readings reported for the calves in the herd-level 
Table 3. Calf management practices statistically associated with serum total protein (TP) readings in calves 1 to $7 \mathrm{~d}$ of age on southern Ontario dairy farms (herd-level study): results of univariable mixed effects linear regression of gender of primary calf caregivers on serum TP readings ${ }^{1}$

\begin{tabular}{|c|c|c|c|c|}
\hline Variable & Response options & $\begin{array}{l}\text { Regression } \\
\text { coefficient }\end{array}$ & $\begin{array}{c}95 \% \text { confidence } \\
\text { interval of coefficient }\end{array}$ & $P$-value \\
\hline Gender of primary calf caregiver(s) & Male & 0 & - & - \\
\hline
\end{tabular}

${ }^{1} \mathrm{n}=404$ calves; number of farms $=111$.

study, and the lack of a significant association between serum TP and sex of the calves. The latter finding has been reported previously (Perino et al., 1995, Filteau et al., 2003) and indicates that any difference that may exist between the rearing of male versus female calves generally has no significant effect on maternal immunity in young calves on southern Ontario dairy farms. The imbalance in male:female ratio among the calves sampled in the calf-level study (i.e., 38.1\% were males and $61.7 \%$ females) reflected the fact that on 2 of the 11 farms in that study, male calves were often sold or transferred to a separate rearing facility within $1 \mathrm{~d}$ of birth. This could potentially have introduced a bias in the analysis of the relationships between sex and serum TP levels, and between sex and risk of FPT. However, it should be noted that there was no apparent male:female imbalance in the herd-level data set. This fact, and the inclusion of a much larger number of herds in the herd-level study, reduces the likelihood that a similar bias could have affected the results of the analyses done using the herd-level data set. Nevertheless, the lack of association between sex of calves and levels of maternal immunity found in the calf-level data set was also found in the herd-level data. In other words, no association was evident in the herd-level data set, where no such bias was apparent.

Analyses of the data with serum TP as the dependent variable yielded different results from those obtained when FPT was used as the dependent variable. Although one of these variables (FPT) is derived from the other (serum TP), they are in fact quite different in nature so that trends seen for the continuous form of the variable may not be apparent when that variable is dichotomized as FPT, and vice versa. Because FPT, rather than serum TP, is known to be associated with calf health outcomes (Robison et al., 1988; Virtala et al., 1999), this may be considered the more useful dependent variable in these analyses. As such, the analyses performed when using serum TP as an outcome provided information that is of use more for research purposes than for practical application. This considered, the proportion of calves showing FPT was much greater (37.1\%) in calves in the herd-level study than in calves in the calf-level study (8.4\%). Because of the large number of farms included in the herd-level study, the greater estimate of prevalence of FPT was less likely to have been influenced by individual farms and more likely to be representative of southern On-

Table 4. Calf management practices statistically associated with the risk of failure of passive transfer (FPT) in calves 1 to $7 \mathrm{~d}$ of age on southern Ontario dairy farms (herd-level study): results of univariable random effects logistic regression of calf management factors on the risk of FPT

\begin{tabular}{|c|c|c|c|c|}
\hline Variable & Response options & $\begin{array}{l}\text { Odds ratio } \\
\text { (or regression coefficient } \\
\text { for continuous variables) }\end{array}$ & $\begin{array}{l}95 \% \text { confidence interval } \\
\text { of odds ratio (or } \\
\text { regression coefficient) }\end{array}$ & $P$-value \\
\hline \multirow{2}{*}{$\begin{array}{l}\text { Calves usually left with dam for } \\
\text { more than } 3 \mathrm{~h} \text { after birth }{ }^{1,2}\end{array}$} & No & 1.00 & - & - \\
\hline & Yes & 2.05 & $1.21,3.46$ & 0.007 \\
\hline $\begin{array}{l}\text { Number of liters of colostrum usually } \\
\text { fed to calves in the first } 6 \mathrm{~h} \text { after birth }\end{array}$ & $\begin{array}{l}\text { Continuous variable (amount } \\
\text { of colostrum in liters) }\end{array}$ & -0.418 & $-0.681,-0.156$ & 0.002 \\
\hline
\end{tabular}

${ }^{1}$ Categories constructed by aggregation of multinomial responses to the original question.

${ }^{2} \mathrm{n}=404$ calves; number of farms $=111$.

${ }^{3} \mathrm{n}=398$ calves; number of farms $=109$. 
Table 5. Calf management practices statistically associated with the risk of failure of passive transfer (FPT) in calves 1 to $7 \mathrm{~d}$ of age on southern Ontario dairy farms (herd-level study): Results of multivariable random effects logistic regression of management variables listed in Table 4, on risk of $\mathrm{FPT}^{1}$

\begin{tabular}{|c|c|c|c|c|}
\hline Variable & Response options & $\begin{array}{l}\text { Odds ratio } \\
\text { (or regression coefficient } \\
\text { for continuous variables) }\end{array}$ & $\begin{array}{l}95 \% \text { confidence interval } \\
\text { of odds ratio (or } \\
\text { regression coefficient) }\end{array}$ & $P$-value \\
\hline $\begin{array}{l}\text { Calves usually left with dam for } \\
\text { more than } 3 \mathrm{~h} \text { after birth }\end{array}$ & $\begin{array}{l}\text { No } \\
\text { Yes }\end{array}$ & $\begin{array}{l}1.00 \\
1.85\end{array}$ & $1.1 \overline{1}, 3.09$ & $\overline{0.019}$ \\
\hline $\begin{array}{l}\text { Number of liters of colostrum usually } \\
\text { fed to calves in the first } 6 \text { h after birth }\end{array}$ & $\begin{array}{l}\text { Continuous variable (amount } \\
\text { of colostrum in liters) }\end{array}$ & -0.373 & $-0.635,-0.111$ & 0.005 \\
\hline
\end{tabular}

${ }^{1} \mathrm{n}=398$ calves; number of farms $=109$. Likelihood-ratio test of rho $=0: \mathrm{X}^{2}=3.82(P=0.025)$.

tario dairy herds in general. Having said this, a FPT prevalence estimate of more than $30 \%$ implies that, on dairy farms within the study area, increased efforts need to be applied to ensure the adequate transfer of maternal immunity to newborn calves.

The results reported here also provide useful data on the methods used on Ontario dairy farms for the storage and feeding of colostrum (Tables 1 and 2). Because farms in the described studies represented a wide spectrum of herd size and management practices, data obtained from these farms were also likely to give a representative overview of calf management practices used by southern Ontario dairy producers.

Most of the predictors used in assessing risk factors for FPT were measured at the herd level, whereas outcomes (serum TP and FPT) were recorded at the calf level. It is therefore possible that the responses recorded for each farm in the study did not apply to all individual calves on that farm. For this reason, factors found to be significantly associated would best be further examined in a future study to verify the existence of such associations. Nevertheless, the variables that were shown here to be associated with passive transfer outcomes all offer biologically plausible explanations for the statistical associations. As such, we believe that these are potentially true predictors of these outcomes in dairy calves in southern Ontario.

The results shown in Tables 4 and 5 indicate that the odds of FPT in calves on farms where producers reported that calves were usually left with their dams for $3 \mathrm{~h}$ or more after birth were nearly twice the odds of FPT as in calves on farms where dams and calves were usually separated within $3 \mathrm{~h}$ of birth. This finding appeared to be supported by the fact that the producerestimated percentage of calves allowed to suckle colostrum directly from their dams also showed a significant and positive association with the risk of FPT in calves. Not surprisingly, these 2 variables were moderately and positively correlated with each other (correlation coefficient 0.22 ). On the other hand, the amount of colostrum that producers reported giving to calves within the first $6 \mathrm{~h}$ of birth showed a significant negative association with the risk of FPT in calves. This variable was moderately and negatively correlated with the former 2 variables (correlation coefficients -0.15 with length of time with the dam and -0.23 with percentage receiving colostrum from the dam). These results would seem to indicate that, as mentioned in other published reports (Besser et al., 1991), calves allowed to remain with and suckle from their dams for more than $3 \mathrm{~h}$ after birth are less likely to receive sufficient colostrum in the first $6 \mathrm{~h}$, and are therefore more likely to develop FPT. Furthermore, calves on farms where the practice is to separate dams and calves as soon as possible after birth are more likely to receive known quantities of colostrum by other means (e.g., bottle or esophageal tube) so that adequate intake of colostrum is more ensured and FPT is less likely (Filteau et al., 2003).

\section{CONCLUSIONS}

Serum refractometry results from 1,340 calves on southern Ontario dairy farms indicated that 78 (8.4\%) of 933 calves 1 to $8 \mathrm{~d}$ of age on 11 farms in the calf-level study fell below the cutoff point $(5.2 \mathrm{~g} / \mathrm{dL})$ for FPT, whereas 151 (37.1\%) of 407 calves 1 to $7 \mathrm{~d}$ of age on 112 farms in the herd-level study showed FPT. No significant association could be demonstrated in either study between serum TP level and sex of the calves. Similarly, there was no demonstrable association between the risk of FPT and sex of the calves. However, gender of the calf caregiver was significantly associated with serum TP levels: TP levels were significantly greater in calves cared for by female caregivers than in those tended by male caregivers. The quantity of colostrum given to calves in the first $6 \mathrm{~h}$ of birth was significantly and negatively associated with the risk of FPT; in addition, the odds of FPT in calves on farms where producers reported that calves were usually left with their dams for $3 \mathrm{~h}$ or more after birth were nearly twice the odds of FPT in calves on farms where dams and calves were 
usually separated within $3 \mathrm{~h}$ of birth. The reporting of similar results from other studies would give weight to these findings. Nonetheless, these results appear to be relevant to the dairy industry in southern Ontario and possibly elsewhere. Therefore, modifications to certain calf management practices could potentially reduce the occurrence of FPT in some southern Ontario herds.

\section{ACKNOWLEDGMENTS}

The authors appreciate the participation of all dairy producers and research technicians involved in data collection. Funding for data analysis and publication was provided by the Ontario Veal Association (Guelph, Ontario, Canada).

\section{REFERENCES}

Besser, T. E., C. C. Gay, and L. Pritchett. 1991. Comparison of three methods of feeding colostrum to dairy calves. J. Am. Vet. Med. Assoc. 198:419-422.

Calloway, C. D., J. W. Tyler, R. K. Tessman, D. Hostetler, and J. Holle. 2002. Comparison of refractometers and test endpoints in the measurement of serum protein concentration to assess passive transfer status in calves. J. Am. Vet. Med. Assoc. 221:1605-1608.

Dohoo, I. R., S. W. Martin, and H. Stryhn. 2003. Model-building strategies. Pages 317-334 in Veterinary Epidemiologic Research. AVC Inc., Charlottetown, Prince Edward Island, Canada.

Donovan, G. A., I. R. Dohoo, D. M. Montgomery, and F. L. Bennett. 1998. Associations between passive immunity and morbidity and mortality in dairy heifers in Florida, USA. Prev. Vet. Med. 34:31-46.

Filteau, V., E. Bouchard, G. Fecteau, L. Dutil, and D. DuTremblay. 2003. Health status and risk factors associated with failure of passive transfer of immunity in newborn beef calves in Quebec. Can. Vet. J. 44:907-913.

Jaster, E. H. 2005. Evaluation of quality, quantity, and timing of colostrum feeding on immunoglobulin $\mathrm{G}_{1}$ absorption in Jersey calves. J. Dairy Sci. 88:296-302.

Morin, D. E., G. C. McCoy, and W. L. Hurley. 1997. Effects of quality, quantity, and timing of colostrum feeding and addition of a dried colostrum supplement on immunoglobulin $\mathrm{G}_{1}$ absorption in Holstein bull calves. J. Dairy Sci. 80:747-753.

Paré, J., M. C. Thurmond, I. A. Gardner, and J. P. Picanso. 1993. Effect of birthweight, total protein, serum IgG and packed cell volume on risk of neonatal diarrhea in calves on two California dairies. Can. J. Vet. Res. 57:241-246.

Perino, L. J., T. E. Wittum, and G. S. Ross. 1995. Effects of various factors on plasma protein and serum immunoglobulin concentrations of calves at postpartum hours 10 and 24. Am. J. Vet. Res. 56:1144-1148.

Quigley, J. D., R. E. Strohbehn, C. J. Kost, and M. M. O’Brien. 2001. Formulation of colostrum supplements, colostrum replacers and acquisition of passive immunity in neonatal calves. J. Dairy Sci. 84:2059-2065.

Robison, J. D., G. H. Stott, and S. K. DeNise. 1988. Effects of passive immunity on growth and survival in the dairy heifer. J. Dairy Sci. 71:1283-1287.

Trotz-Williams, L. A., S. W. Martin, K. E. Leslie, T. Duffield, D. Nydam, and A. S. Peregrine. 2007a. Calf-level risk factors for neonatal diarrhea and shedding of Cryptosporidium parvum in Ontario dairy calves. Prev. Vet. Med. 82:12-28.

Trotz-Williams, L. A., S. W. Martin, K. E. Leslie, T. Duffield, D. Nydam, and A. S. Peregrine. 2007b. Association between management practices and within-herd prevalence of Cryptosporidium parvum shedding on dairy farms in southern Ontario. Prev. Vet. Med. 83:11-23.

Virtala, A. M., Y. T. Grahn, G. D. Mechor, and H. N. Erb. 1999. The effect of maternally derived immunoglobulin $G$ on the risk of respiratory disease in heifers during the first 3 months in life. Prev. Vet. Med. 39:35-37.

Wallace, M. M., B. D. Jarvie, N. R. Perkins, and K. E. Leslie. 2006. A comparison of serum harvesting methods and type of refractometer for determining total solids to estimate failure of passive transfer in calves. Can. Vet. J. 47:573-575. 